\title{
Impact of Sequelae Resulting From the COVID-19 Pandemic on Mental Health: a Cross-sectional Study in Japan and Sweden
}

Kazuki Matsumoto

Chiba University

Sayo Hamatani ( $\square$ ahna0286@chiba-u.jp )

Chiba University

Eiji Shimizu

Chiba University

Anton Käll

Linköping University

Gerhard Andersson

Linköping University

\section{Research Article}

Keywords: Coronavirus disease 2019 (COVID-19), COVID-19 pandemic, severe acute respiratory syndrome coronavirus 2 (SARS-CoV-2), SARS-CoV-2, depression, anxiety, mental health, sequelae

Posted Date: October 8th, 2021

DOI: https://doi.org/10.21203/rs.3.rs-798323/v1

License: (1) This work is licensed under a Creative Commons Attribution 4.0 International License.

Read Full License 


\section{The title}

Impact of sequelae resulting from the COVID-19 pandemic on mental health: A crosssectional study in Japan and Sweden

The full names of the authors followed by their academic degrees Kazuki Matsumoto, ${ }^{1,2} \mathrm{PhD}$; Sayo Hamatani, ${ }^{1,3 *} \mathrm{PhD}$; Eiji Shimizu, ${ }^{1,4} \mathrm{MD} ., \mathrm{PhD}$; Anton Käll5; Gerhard Andersson, ${ }^{5,6} \mathrm{PhD}$.

\section{The full names of institutions affiliated by the authors}

${ }^{1}$ Research Center for Child Mental Development, Chiba University, Chiba, Japan

${ }^{2}$ Laboratory of Neuropsychology, Kanazawa University, Ishikawa, Japan

${ }^{3}$ Research Center for Child Mental Development, University of Fukui, Fukui, Japan

${ }^{4}$ Department of Cognitive Behavioral Physiology, Graduate School of Medicine, Chiba University, Chiba, Japan

${ }^{5}$ Department of Behavioural Sciences and Learning, Department of Biomedical and Clinical Sciences, Linköping University, Linköping, Sweden

${ }^{6}$ Department of Clinical Neuroscience, Karolinska Institute, Stockholm, Sweden

\section{*Corresponding author}

Sayo Hamatani, $\mathrm{PhD}$

Research Center for Child Mental Development, Chiba University, Chiba, Japan

Inohana 1-8-1, Chuo-ku, Chiba City, Chiba, Japan

Email: ahna0286@chiba-u.jp

Tel: 043-226-2975 / Fax: 043-226-8588

ORCiD: https://orcild.org/0000-0001-7847-6381 


\section{Abstract (301 within 350 words)}

Background: Due to the coronavirus disease 2019 (COVID-19) pandemic, people have undermined their mental health. It has been reported that sequelae resulting from COVID-19 occur at a certain rate. However, information on the mental health of people with sequelae is limited. Thus, this study investigated the relationship between sequelae resulting from COVID-19 and mental health.

Methods: Design of the present study was an International and collaborative crosssectional study in Japan and Sweden from March 18 to June 15, 2021. The analyzed data included 763 adults who participated in online surveys in Japan and Sweden and submitted complete data. In addition to demographic data including terms related to COVID-19, psychiatric symptoms such as depression, anxiety, and post-traumatic stress were measured by using the fear of COVID-19 scale (FCV-19S), Patient Health Questionnaire-9 (PHQ-9), General Anxiety Disorder-7 item (GAD-7), and Impact of Event Scale-Revised (IES-R).

Results: of the 135 COVID-19 survivors among the 763 total participants, $40.7 \%$ had COVID-19-related sequelae. First, the results of the Bonferroni-corrected Mann Whitney U test showed that the group infected SARS-CoV-2 with sequelae scored significantly higher than those without sequelae and the non-infected group on all clinical symptom scales $(\mathrm{P} \leq .001)$. Next, there was a significant difference that incidence rates of clinical-significant psychiatric symptoms among each group from the results of the Chi-squared test $(\mathrm{P} \leq .001)$. Finally, the results of the multivariate logistic model revealed that the risk of having more severe clinical symptoms were $2.48-4.64$ times higher among participants with sequelae. 
Conclusion: The results showed that approximately half had sequelae after COVID-19 and that the sequelae of COVID-19 may lead to the onset of mental disorders.

Trial registration: The ethics committee of Chiba University approved this crosssectional study (approval number: 4129). However, as no medical intervention was conducted, a clinical trial registration was not necessary.

\section{Keywords}

Coronavirus disease 2019 (COVID-19), COVID-19 pandemic, severe acute respiratory syndrome coronavirus 2 (SARS-CoV-2), SARS-CoV-2, depression, anxiety, mental health, sequelae

\section{Background}

Coronavirus disease 2019 (COVID-2019) caused by severe acute respiratory syndrome coronavirus 2 (SARS-CoV-2) is an ongoing global pandemic. The clinical outcome of COVID-19 ranges from mild respiratory failure to severe disease with high risk of fatality. ${ }^{1}$ As of July 26, 2021, the global COVID-19 dashboard shows 194,723,719 coronavirus case patients, $4,167,618$ deaths. ${ }^{2}$ Recent studies have reported that at least the one in four COVID-19 recoverees suffer long-term impairments such as fatigue and taste/smell disorders. ${ }^{3}$ A decrease in the ability of the lungs to diffuse carbon monoxide was often found in patients who recovered from COVID- $19,{ }^{4}$ suggesting that respiratory dysfunction may remain after recovery. ${ }^{5}$ A recent study by Ballan and colleagues followed up patients three to four months after COVID-19 recovery and reported the following long-term sequelae: 13 (5.5\%) Dyspnea, 12 (5.0\%) ageusia, 11 (4.6\%) 
anosmia, 14 (5.9\%) arthralgia, 14 (5.9\%) myalgia, and 53 (22.3\%) limited mobility and $113(51.6 \%)$ decreased vital capacity. ${ }^{6}$

Additionally, there is also a need to focus on mental health problems as a sequela of COVID-19. Mental health problems such as symptoms of post-traumatic stress disorder (PTSD), depression, or anxiety has been observed in people who recovered from COVID-19. ${ }^{6,7}$ Anxiety and depression may be common six months after COVID-19 recovery, and people who present a more serious condition in the acute phase of COVID-19 are more likely to develop symptoms of depression and anxiety. ${ }^{8}$ Those long-term effects are in line with the previous severe acute respiratory syndrome (SARS). ${ }^{9}$ It has been reported that sequelae and mental disorders occur after COVID19 , though the relationship between them has been not insufficiently investigated. Somatic diseases are often related to symptoms of mental disorders, including major depressive disorder ${ }^{10}$ and the relationship between respiratory symptoms as sequelae after COVID-19 and mental health are strong. ${ }^{11}$ Thus, identifying COVID-19 patients who are most likely to need assistance due to physical and psychiatric symptoms can have implications for long-term support policies for COVID-19-infected individuals.

The objectives of the present study were to investigate the prevalence of sequelae after COVID-19, and clinical associations between post-recovery physical function and psychosocial disorders in individuals who had been infected with SARSCoV-2. We report the results of COVID-19 sequelae and their effects on the mental health of study participants in Japan and Sweden. 


\section{Methods}

\section{Study Design}

We conducted a cross-sectional study in Japan and Sweden from March 18 to June 15, 2021 and collected the data through an online survey. The only eligibility criterion was that the age of the participants should be at least 18 years old. Data collection was outsourced to Asmark companies in Japan and Prolific in Sweden, and data collection was carried out through each company's online research platform. Participants answered the questions by accessing the websites. They were informed in the first half of the questionnaire that the survey content included information about the COVID-19 hospitalization experience and sequelae, so participants could withdraw their participation, if they wished, depending on the degree of psychological distress. A small monetary compensation was paid as a reward to the participants through the research company.

The study was planned and designed by researchers in Japan and Sweden according to the STROBE statement (see the STROBE checklist in the Supplementary File 1 for details). ${ }^{12}$ The protocol for the current observational study was reviewed and approved by the Chiba University Graduate School of Medicine Ethics Review Committee (approval number 4129). The online survey was written in the native languages of Japan and Sweden, and it took about 20 minutes to complete.

\section{Setting}

We recruited 763 participants from Japan and Sweden, including 200 COVID-19 survivors. Data were collected in Japan from March 18 to 22, 2021 and in Sweden from April 5 to June 15, 2021 (e.g., a slight difference in time).

\section{Outcomes}


We collected the following background information about the of the participants: age, gender (woman, male and prefer not to say), race, occupation (regular, non-regular, unemployed, college student), family structure (living with family, living alone, sharing a house with someone other than the family), academic background, financial situation (household annual income of less than 4270,000 JPY (about 38,366 dollars) or more/ 380,000 SEK (about 44,408 dollars or more), having enough savings to live for about half a year if you lose your current job (yes, no), living area (up to prefecture), history of mental illness (depression, bipolar disorder, schizophrenia, anxiety, PTSD, obsessive-compulsive disorder, panic disorder, eating disorder, substance use disorder, etc.; free description), presence or absence of history of physical illness (high blood pressure, asthma, diabetes, etc.; free description). We collected information about COVID-19 (presence of infection, time of infection, time required for recovery, acute symptoms, physical sequelae, and vaccination). Mental health was evaluated using the following measures: the fear of COVID-19 scale (FCV-19S); ${ }^{13,14}$ Patient Health Questionnaire-9 (PHQ-9); ${ }^{15}{ }^{16}$ General Anxiety Disorder-7 -item (GAD-7); ${ }^{17}, 18$ Impact of Event Scale-Revised (IES-R). ${ }^{19,20}$

\section{Dealing with bias}

People who have been recovering for some time may not be able to remember the early aftereffects of recovery following a COVID-19 infection. To address this potential recall bias, we asked about sequelae and mental health at the time of the survey. Because the data were collected via the internet, there may be a selection bias as the survey only reach those who have access to the internet and are interested in health. To address this selection bias, we conducted the survey in two countries (Japan and Sweden) in which internet usage is extremely high. Internet usage rates have been over 
$90 \%$ in both countries for a long time. ${ }^{21}$ Although there are some regulations in both countries, strict lockdown has never been implemented since the onset of the COVID19 pandemic. Therefore, we assumed that ordinary people in both countries 2021 would be interested in a survey on COVID-19.

\section{Sample size}

The assumed effect size calculated by G*Power was 0.30 , two-tail. The power was set at 0.80 and the significance level at .05 . The sample size needed to obtain sufficient power by the $F$ test was estimated to be 37 people in each group (non-infected group, infected without sequelae, and infected with sequelae). To collect at least 74 infected people, the final total sample size was set to 800 after taking into account the proportion of infected people and missing data.

\section{Statistical analysis}

We used SPSS version 26 (IBM Corporation, Armonk, NY, USA) for our statistical analyses. A two-sided P value of $<.05$ was considered statistically significant. First, we conducted the Kruskal-Wallis tests among the uninfected people, the infected people with sequelae, and those without sequelae, before conducting the Bonferroni-corrected Mann-Whitney U test for multiple comparisons to verify if there was a significant difference in clinical symptoms of mental stress. Next, we conducted a Chi-squared test to compare the three groups mentioned above and verify if there was a significant difference in the proportion of people at high risk of clinically significant mental illness. Finally, we conducted logistic regression analyses to evaluate the impact of sequelae on mental health between the participants infected with sequelae and those without. In a logistic regression model, we assessed whether the nine variables (age, country, gender, mental illness, physical illness, days to recovery, hospitalization, sequelae, and 
ventilator) were associated with determinants of clinical symptom incidence. In the logistic regression model, we also calculated the adjusted odds ratio (OR) with a $95 \%$ confidence interval (CI) for the risk of clinically significant symptoms of depression, anxiety, and post-traumatic stress for the participants with sequelae after COVID-19. We used cutoffs as the criterion for the incidence of each clinical measure. The cutoff for FCV-19S was 18 points or more, ${ }^{13,14} 22$ points or more for PHQ-9, ${ }^{15}, 1623$ points or more for GAD-7, ${ }^{17,18}$ and 25 points or more for the IES-R. ${ }^{19,20}$

\section{Results}

\section{The demographic data of participants}

Table 1 presents demographic data. Of the 763 participants, 135 were infected and 628 were not. There were 269 women $(35.3 \%), 487$ men (63.8\%), and 7 who preferred not to state their gender $(0.9 \%)$. Table 2 shows the history of mental illness and physical illness, presence or absence of hospitalization, presence or absence of a respirator, number of days until recovery, symptoms at the time of infection, and sequelae. There were 40 (46.0\%) Japanese and 15 (31.3\%) Swedish participants who still had COVID19 symptoms (sequelae). Among the Japanese, the main sequelae were olfactory dysfunction $(n=7,12.6 \%)$, dysgeusia $(n=11,12.6 \%)$, fatigue $(n=10,11.5 \%)$, chest pain $(n=6,6.9 \%)$, coughing $(n=6,6.9 \%)$, and palpitations $(n=5,5.7 \%)$. Among the Swedes, the main sequelae were fatigue $(n=9,18.8 \%)$, olfactory dysfunction $(n=5$, $10.4 \%)$, fever $(n=3,6.3 \%)$, and depression $(n=3,6.3 \%)$.

Table 1. Here.

Table 2. Here. 


\section{Resulst of menal health between the groups}

Figure 1 show that the results of the Kruskal-Wallis-test, there were significant differences on the following clinical symptom scales: FCV-19S $(\mathrm{H}(2)=23.8, \mathrm{P}$ $\leq .001)$, PHQ-9 $(\mathrm{H}(2)=22.4, \mathrm{P} \leq .001)$, GAD-7 $(\mathrm{H}(2)=25.4, \mathrm{P} \leq .001)$, and IES-R $(\mathrm{H}$ $(2)=30.8, \mathrm{P} \leq .001)$. In a comparison between the groups by the Bonferroni-corrected Mann Whitney U test, the group infected SARS-CoV-2 with sequelae scored significantly higher than those without sequelae and the non-infected group on all clinical symptom scales $(\mathrm{P} \leq .001)$. There was no significant difference between infected group without sequelae and non-infected groups.

Figure 1. Here

Figure 2 shows the incidence of clinically significant psychiatric symptoms in each group. Among the participants, 269 (42.8\%) of the non-infected group, 35 (43.8\%) of the infected without sequelae group, and $40(72.7 \%)$ of the infected with sequelae group showed significant symptoms of COVID-19 fear, as measured by FCV-19S. Additionally, 190 (30.3\%) of the non-infected group, $21(26.3 \%)$ of the infected without sequelae group, and $32(58.2 \%)$ of the infected with sequelae group displayed significant symptoms of depression, as measured by PHQ-9, while 15 (16.1\%) of the non-infected group, $9(11.3 \%)$ of the infected without sequelae group, and 24 (43.6\%) of the infected with sequelae group displayed significant symptoms of anxiety, as measured by GAD-7. In terms of posttraumatic stress, 192 (30.6\%) of the non-infected group, $31(38.8 \%)$ of the infected without sequelae group, and $37(67.3 \%)$ of the infected with sequelae group displayed significant symptoms, as measured by ISE-R. Regarding the incidence of clinically significant psychiatric symptoms between the 
three groups, the results of the Chi-squared test showed a significant difference in all of the above scales $(\mathrm{P} \leq .001)$.

Figure 2. Here.

\section{Impact of COVID-19 sequelae on mental health}

The results of the multivariate logistic model revealed that the risks of having more severe scores on all clinical scales (FCV-19S, PHQ-9, GAD-7, and ISE-R) were 2.476 to 4.638 times higher among patients with sequelae: FCV-19S: 4.06 (95\% CI:-1.56510.560); PHQ-9: 3.380 (95\% CI: 1.541-7.412); GAD-7: 4.638 (95\% CI: 1.72-12.509); ISE-R: 2.476 (95\% CI: 1.147-5.342) (see Table 3).

Table 3. Here.

\section{Discussion}

\section{The principal findings}

The objective of the present study was to identify the sequelae after COVID-19 and investigate the relationship between sequelae and mental health status. We conducted an online survey in two countries and collected valid responses from a total of 763 participants, including 135 with a history of COVID-19. Of the 135 participants after COVID-19, 40.7\% $(\mathrm{n}=55 / 135)$ had some sequelae of COVID-19. The major physical sequelae of COVID-19 reported were olfactory disorder (10.4 to $12.6 \%$ ), dysgeusia ( $4.2 \%$ to $12.6 \%)$, and malaise $(11.5 \%$ to $18.8 \%)$. The COVID-19-infected respondents showed greater incidence of all mental health symptoms investigated in this study, including symptoms of COVID-19-related anxiety, depression, generalized anxiety, and post-traumatic stress. Greater impairment of mental health was observed in COVID-19 infected respondents with sequelae than in those without sequelae. Furthermore, the 
results of our logistic regression analysis suggested that mental health was impaired in the presence of sequelae after COVID-19.

\section{The implications of the findings}

In the study, $43.0 \%(n=58 / 135)$ of the participants after COVID-19 scored in the psychopathological range on the self-assessed psychological scales suggesting that they may meet the criteria for a mental disorder; $39.3 \%(n=53 / 135)$ may have had depression, 24.4\% $(n=33 / 135)$, anxiety disorder, and 50.4\% $(n=68 / 135)$, PTSD. The participants infected SARS-CoV-2 had significant psychiatric symptoms compared to the participants had not be infected. The results are consistent with those of (i) a cohort study of inpatients with COVID-19 for a one-month period in Helsinki, ${ }^{25}$ (ii) a British community cohort study, ${ }^{26}$ and (iii) an American electronic health record network cohort study. ${ }^{27}$ The latest systematic review shows that the incidence of depressive symptoms is $10.0-68.5 \%$, that of clinically significant anxiety is $5.0-55.2 \%$, acute and post-traumatic stress is $7.0-36.4 \%$, and fatigue is $12.7-88.6 \%{ }^{28}$ The evidence indicates that SARS-CoV-2 infection may increase the risk of developing mental disorders such as depression, anxiety disorders, and PTSD. ${ }^{27}$

The incidence of long-term COVID-19 health hazards was $40.7 \%(\mathrm{n}=55 / 135)$ after COVID-19 among Japanese and Swedish participants in the present study; relatively common sequelae were cough $(40.1 \%)$, malaise $(14.1 \%)$, dysgeusia $(9.6 \%)$, and olfactory disorder (8.9\%). The most frequently observed sequela of COVID-19 in our study is cough. These results are consistent with previous studies in which most patients had abnormal respiratory function at 3 months,${ }^{29}$ meaning that patients with acute symptoms of COVID-19 that were severe enough to require occasional ventilation 
may have impaired long-term respiratory function. Fatigue was reported at $14.1 \%$ in infected respondents in this study. Fatigue after COVID-19 may be associated with lung, cardiovascular, liver, kidney, cognitive, and neural function in some SARS-CoV-2 infected individuals experiencing serious complications during the acute phase. ${ }^{30-34}$

Furthermore, the logistic regression analysis showed that the participants with sequelae after COVID-19 were at a higher risk of developing mental disorders than those without sequelae. Historically, non-major symptoms of infectious diseases have been neglected; a COVID-19 long-hauler reported that his medical doctor/practitioners disbelieved his physiological distress. ${ }^{35}$ The results from our study can provide practitioners and clinicians with evidence of late-onset long-term symptoms in SARSCoV-2 infected individuals and suggestions for the risk of subsequent development of mental disorders. The findings also contain information that will help medical policymakers make decisions, highlighting the need to provide long-term medicalpsychosocial support services to patients infected SARS-CoV-2.

Of the non-infected people in the present study, 30.3\% exceeded the PHQ-9 cutoff. Our finding is similar to the results of the latest meta-analysis that reported that the pooled prevalence of depression during the COVID-19 pandemic was $25 \%$ (ranging from $7.45 \%$ to $48.3 \%) .{ }^{36}$ Therefore, although caution is required in the interpretation due to the non-random sampling procedure, our results indicate that clinically significant depressive symptoms in the general population in Japan and Sweden might be common during the COVID-19 pandemic. In the United States, Ettman et al. (2020) reported that the prevalence of clinical significantly depressive symptoms (the total PHQ-9 score $\geq 10$ ) in the general population increased from $8.5 \%$ to $27.8 \%$ during the COVID-19 pandemic. ${ }^{37}$ Without public health crises such as the COVID-19 pandemic, 
the ratio of PHQ-9 scores above this threshold for the general adult population has been approximately 6\%: 6.5\% in South Korea, 5.7\% in Japan, and 6.4\% in 27 European countries. ${ }^{38}$ A recent meta-analysis also suggested a one-year prevalence of depression of $7.2 \%$ in 30 countries around the world. ${ }^{39}$ Hence, our results add to previous studies by suggesting a significant impact on mental health in the general population from the COVID-19 pandemic.

\section{Strengths, Limitations, and directions for future research}

The present research has four strengths. First, our results suggest that COVID-19 sequelae represent a risk for mental illness, and they have deepened our knowledge of the relationship between sequelae of COVID-19 and mental disorders. Second, participants in the present study also included data on patients with relatively mild COVID-19 who have not been hospitalized. Thus, the findings of this study may be applicable to patients with differing severities of COVID-19. Third, the present study population was diverse because this study was conducted in two geographical regions, Eastern Asia and Northern Europe (Table 1). The fourth strength is that the participants have not been intentionally exposed and treated by a particular medical facility because the present research was an online study of cross-sectional study design (Wang and Cheng, 2020)..$^{40}$

The limitations of the present study include the nature of the sample, the test format, and accessibility. First, in the survey most respondents were adults in their $20 \mathrm{~s}$ and $30 \mathrm{~s}$ in the Swedish data set. In contrast, there were few respondents aged 50 years or older. Elderly people, who often have chronic physical illnesses, are a group that demonstrate more serious symptoms of COVID-19, ${ }^{41,42}$ which can be more detrimental 
to sequelae and mental health. ${ }^{43}$ In future studies, conducting research with a larger sample size and analyzing them by age group is necessary. Second, all mental health measures were rated on a self-rating scale. Although the data collected was wellvalidated and the severity of clinical symptoms was credible, clinical symptoms alone do not confirm any mental disorders. In the future, cross-sectional populations should be assessed using telephone interview and using diagnostic classification tests conducted in semi-structured interviews by trained clinicians. The final limitation was that the population may have belonged to a relatively wealthy social class with a high degree of education, information and communication technology (ICT) literacy, and possession of an internet environment and devices. Populations who have access to the current online research will probably have more opportunities to learn about coping strategies and receive medical services for sequelae, as they will also have access to appropriate medical information via the internet. The prognosis of COVID-19 may be worse than the results of this study when a population sample with low ICT literacy and low education level is included. That is, the results of this study may have provided more optimistic data. For future research, it is recommended to include community samples through face-to-face assessment.

\section{Conclusions}

The result of our research suggests that sequelae occur in about $40 \%$ after COVID-19. The SARS-CoV-2 infection may cause long- and short-term health hazards and increase the risk of mental disorders. Therefore, medical policy regarding COVID-19 should include long-term clinical practice to address long-term symptoms and mental health risks. 


\section{List of abbreviations}

COVID-19: Coronavirus disease 2019

FCV-19S:: Fear of COVID-19 Scale

GAD-7: General Anxiety Disorder-7 -item

ICT: Information and Communication Technology

IES-R: Impact of Event Scale-Revised

PHQ-9: Patient Health Questionnaire-9

PTSD: Post-Traumatic Stress Disorder

SARS-CoV-2: Severe Acute Respiratory Syndrome Coronavirus 2

\section{(i) Disclosure statement}

\section{Ethics approval and consent to participante}

The protocol for the current observational study was reviewed and approved by the Chiba University Graduate School of Medicine Ethics Review Committee (approval number 4129). The current research was conducted in accordance with the "Ethical Guidelines for Life Science and Medical Research for Human," which is guideline for clinical research in Japan and the provisions of the Declaration of Helsinki. Participants were explained in an online survey that answering questions would be considered consent. Participants have effective discernment because they are adults over the age of 18 and ICT skills are required to response questions on the website. Therefore, in the current research, consent was obtained only from the individual, even if he / she had a mental illness; the Institutional Review Board determined that consent from a guardian 
or guardian was not required. In addition, the need for ethics approval was deemed unnecessary according to national Swedish regulations as no identifiable sensitive personal data were collected "Law (2003:460) on ethics review of research involving humans".

\section{Consent for publication}

NOT APPLICABLE.

\section{Availability of data and materials}

The datasets analysed during the current study available from the corresponding author on reasonable request.

\section{Competing intersts}

The authors declare no conflicts of interest associated with this manuscript.

\section{Funding}

The present research was supported by the Daiwa Securities Health Foundation Ordinance 2nd Year Coronavirus Infectious Diseases (COVID-19) Research Grant "COVID-19 International Comparative Study on Mental Health of Infected Persons". Authors' contributions

\section{Author Contributions}

$\mathrm{KM}, \mathrm{SH}$, ES, and GA contributed to the concept and design. KM, SH, and AK performed acquisition and interpretation of data. $\mathrm{KM}$ and $\mathrm{SH}$ drafted the manuscript. SH performed statistical analysis and obtained funding for the present study. ES, and GA supervised the overall conduct of the study. All authors contributed to critical revision of the manuscript for important intellectual content.

\section{Ackowlegements}


We would like to express our utmost gratitude to the participants. We wish to thank George Vlaescu for his role as webmaster in the survey.

\section{(ii) Figure legends}

Figure 1. The results of the Kruskal-Wallis test

Figure 2 . The incidence of clinically significant psychiatric symptoms

\section{(iii) References}

1 Chen N, Zhou M, Dong X, et al. Epidemiological and clinical characteristics of 99 cases of 2019 novel coronavirus pneumonia in Wuhan, China: a descriptive study. Lancet. 2020; 395: 507-513. doi:10.1016/S0140-6736(20)30211-7

2 COVID-19 Data Repository by the Center for Systems Science and Engineering (CSSE) at Johns Hopkins University.

https://www.arcgis.com/apps/opsdashboard/index.html\#/bda7594740fd4029942346 7b48e9ecf6. Accessed July 26, 2021.

3 Logue JK, Franko NM, McCulloch DJ, et al. Sequelae in Adults at 6 Months After COVID-19 Infection. JAMA Netw Open. 2021; 4: e210830.

doi:10.1001/jamanetworkopen.2021.0830

4 Mo X, Jian W, Su Z, et al. Abnormal pulmonary function in COVID-19 patients at time of hospital discharge. Eur Respir J. 2020; 55: 2001217. doi: $10.1183 / 13993003.01217-2020$ 
5 Ngai JC, Ko FW, Ng SS, To KW, Tong M, Hui DS. The long-term impact of severe acute respiratory syndrome on pulmonary function, exercise capacity and health status. Respirology. 2010; 15: 543-550. doi:10.1111/j.1440-1843.2010.01720.x

6 Bellan M, Soddu D, Balbo PE, et al. Respiratory and Psychophysical Sequelae Among Patients With COVID-19 Four Months After Hospital Discharge. JAMA Netw Open. 2021; 4: e2036142. doi: 10.1001/jamanetworkopen.2020.36142

7 Xiong Q, Xu M, Li J et al. Clinical sequelae of COVID-19 survivors in Wuhan, China: a single-center longitudinal study. Clin Microbiol and Infect. 2021; 27: 89-

\section{5. doi:10.1016/j.cmi.2020.09.023}

8 Huang C, Huang L, Wang Y et al. 6-month consequences of COVID-19 in patients discharged from hospital: a cohort study. Lancet. 2021; 397: 220-232. doi:10.1016/S0140-6736(20)32656-8

9 Tansey CM, Louie M, Loeb M, et al. One-year outcomes and health care utilization in survivors of severe acute respiratory syndrome. Arch Intern Med. 2007; 167: 1312-1320. doi:10.1001/archinte.167.12.1312

10 Goodwin GM. Depression and associated physical diseases and symptoms. Dialogues Clin Neurosci. 2006; 8: 259-265.

doi:10.31887/DCNS.2006.8.2/mgoodwin

11 Leander M, Lampa E, Rask-Andersen A et al. Impact of anxiety and depression on respiratory symptoms. Respir Med. 2014; 108: 1594-1600. doi:10.1016/j.rmed.2014.09.007

12 von Elm E, Altman DG, Egger M, et al. The Strengthening the Reporting of Observational Studies in Epidemiology (STROBE) statement: guidelines for 
reporting observational studies. Lancet. 2007; 370: 1453-1457. doi:10.1016/S01406736(07)61602-X

13 Ahorsu DK, Lin CY, Imani V, Saffari M, Griffiths MD, Pakpour AH. The Fear of COVID-19 Scale: Development and Initial Validation. Int J Ment Health Addict. 2020;1-9. doi:10.1007/s11469-020-00270-8

14 Midorikawa H, Aiba M, Lebowitz A, et al. Confirming validity of The Fear of COVID-19 Scale in Japanese with a nationwide large-scale sample. PLoS One. 2021; 16: e0246840. doi:10.1371/journal.pone.0246840

15 Spitzer RL, Williams JB, Kroenke K, Hornyak R, McMurray J. Validity and utility of the PRIME-MD patient health questionnaire in assessment of 3000 obstetricgynecologic patients: the PRIME-MD Patient Health Questionnaire ObstetricsGynecology Study. Am J Obstet Gynecol. 2000; 183: 759-769. doi:10.1067/mob.2000.106580

16 Muramatsu K, Miyaoka H, Kamijima K, et al. Performance of the Japanese version of the Patient Health Questionnaire-9 (J-PHQ-9) for depression in primary care. Gen Hosp Psychiatry. 2018; 52: 64-69. doi:10.1016/j.genhosppsych.2018.03.007

17 Swinson RP. The GAD-7 scale was accurate for diagnosing generalised anxiety disorder. Evid Based Med. 2006; 11: 184. doi:10.1136/ebm.11.6.184

18 Matsumura K. An up-to-date letter in the Japanese version of PHQ, PHQ-9, PHQ15. Niigata Seiryo University Graduate School of Clinical Psychology Research. 2014; 7: 35-39. doi:10.32147/00001605

19 Weiss DS, Marmar CR. The impact of the Event Scale-Revised. In Wilson JP and Keane TM (Eds), Assessing psychological trauma and PTSD: A practitioner's handbook (pp 399-411). New York: Guilford Press; 1997 
20 Asukai N, Kato H, Kawamura N, et al. Reliability and validity of the Japaneselanguage version of the impact of event scale-revised (IES-R-J): four studies of different traumatic events. $J$ Nerv Ment Dis. 2002; 190: 175-182.

doi:10.1097/00005053-200203000-00006

21 Max Roser, Hannah Ritchie and Esteban Ortiz-Ospina (2015) - "Internet". Published online at OurWorldInData.org. https://ourworldindata.org/internet. Accessed June 27, 2021.

22 Mohsen F, Bakkar B, Alsrouji SK, et al. Fear among Syrians: a Proposed Cutoff Score and Volition of the Arabic Fear of COVID-19 Scale-A National Survey. medRxiv. https://www.medrxiv.org/content/10.1101/2021.05.25.21257637v1.full. Accessed June 27, 2021.

23 Kroenke K, Spitzer RL, Williams JB. The PHQ-9: validity of a brief depression severity measure. J Gen Intern Med. 2001; 16: 606-613. doi:10.1046/j.15251497.2001.016009606.x

24 Spitzer RL, Kroenke K, Williams JB, Löwe B. A brief measure for assessing generalized anxiety disorder: the GAD-7. Arch Intern Med. 2006; 166: 1092-1097. doi:10.1001/archinte.166.10.1092

25 Mazza MG, De Lorenzo R, Conte C et al. Anxiety and depression in COVID-19 survivors: Role of inflammatory and clinical predictors. Brain Behav Immun. 2020; 89: 594-600. doi:10.1016/j.bbi.2020.07.037

26 Jia R, Ayling K, Chalder T, et al. Mental health in the UK during the COVID-19 pandemic: cross-sectional analyses from a community cohort study. BMJ Open. 2020; 10: e040620. doi:10.1136/bmjopen-2020-040620 
27 Taquet M, Luciano S, Geddes JR, Harrison PJ. Bidirectional associations between COVID-19 and psychiatric disorder: retrospective cohort studies of 62354 COVID19 cases in the USA. Lancet Psychiatry. 2021; 8: 130-140. doi:10.1016/S22150366(20)30462-4

28 Vanderlind WM, Rabinovitz BB, Miao IY et al. A systematic review of neuropsychological and psychiatric sequalae of COVID-19: implications for treatment. Curr Opin Psychiatry. 2021; 34: 420-433. doi:10.1097/YCO.0000000000000713

29 van Gassel RJJ, Bels JLM, Raafs A et al. High Prevalence of Pulmonary Sequelae at 3 Months after Hospital Discharge in Mechanically Ventilated Survivors of COVID-19. Am J Respir Crit Care Med. 2021; 203: 371-374. doi:10.1164/rccm.202010-3823LE

30 Bonow RO, O'Gara PT, Yancy CW. Cardiology and COVID-19. JAMA. 2020; 324: 1131-1132. doi:10.1001/jama.2020.15088

31 Leung TYM, Chan AYL, Chan EW, et al. Short- and potential long-term adverse health outcomes of COVID-19: a rapid review. Emerg Microbes Infect. 2020; 9: 2190-2199. doi:10.1080/22221751.2020.1825914

32 Daugherty SE, Guo Y, Heath K et al. Risk of clinical sequelae after the acute phase of SARS-CoV-2 infection: retrospective cohort study. BMJ. 2021; 373: 1098. doi:10.1136/bmj.n1098

33 Josephson SA, Kamel H. Neurology and COVID-19. JAMA. 2020; 324: 1139-1140. doi:10.1001/jama.2020.14254

34 Winkelmayer WC, Khairallah P, Charytan DM. Nephrology and COVID-19. JAMA. 2020; 324: 1137-1138. doi:10.1001/jama.2020.16779 
35 Honigsbaum M, Krishnan L. Taking pandemic sequelae seriously: from the Russian influenza to COVID-19 long-haulers. Lancet. 2020; 396: 1389-1391. doi:10.1016/S0140-6736(20)32134-6

36 Bueno-Notivol J, Gracia-García P, Olaya B, et al. Prevalence of depression during the COVID-19 outbreak: A meta-analysis of community-based studies. Int J Clin Health Psychol. 2021; 21: 100196. doi:10.1016/j.ijchp.2020.07.007

37 Ettman CK, Abdalla SM, Cohen GH, et al. Prevalence of Depression Symptoms in US Adults Before and During the COVID-19 Pandemic. JAMA Netw Open. 2020; 3: e2019686. doi:10.1001/jamanetworkopen.2020.19686

38 Arias-de la Torre J, Vilagut G, Ronaldson A, et al. Prevalence and variability of current depressive disorder in 27 European countries: a population-based study. Lancet Public Health. 2021; S2468-2667: 00047-5. doi:10.1016/S24682667(21)00047-5

39 Lim GY, Tam WW, Lu Y, et al. Prevalence of Depression in the Community from 30 Countries between 1994 and 2014. Sci Rep. 2018; 8: 2861. doi:10.1038/s41598-01821243-x

40 Wang X, Cheng Z. Cross-Sectional Studies: Strengths, Weaknesses, and Recommendations. Chest. 2020; 158: S65-S71. doi:10.1016/j.chest.2020.03.012

41 D'ascanio M, Innammorato M, Pasquariello L et al. Age is not the only risk factor in COVID-19: the role of comorbidities and of long staying in residential care homes. BMC Geriatr. 2021; 21: 63. doi:10.1186/s12877-021-02013-3

42 Liu K, Chen Y, Lin R, Han K. Clinical features of COVID-19 in elderly patients: A comparison with young and middle-aged patients. $J$ Infect. 2020; 80: e14-e18. doi:10.1016/j.jinf.2020.03.005 
43 Araújo MPD, Nunes VMA, Costa LA, Souza TA, Torres GV, Nobre TTX. Health conditions of potential risk for severe Covid-19 in institutionalized elderly people. PLoS One. 2021;16: e0245432. doi:10.1371/journal.pone.0245432

\section{(ixi) A list of supporting information if relevant}

None. 


\section{(iv) Tables}

Table 1. Demographic data of the participants

\begin{tabular}{|c|c|c|c|c|c|c|c|c|c|}
\hline & \multicolumn{3}{|l|}{ Overview } & \multicolumn{3}{|l|}{ Japanese } & \multicolumn{3}{|l|}{ Swedish } \\
\hline & $\begin{array}{l}\text { Total } \\
(\mathrm{n}=763)\end{array}$ & $\begin{array}{l}\text { Non-infected } \\
\text { people } \\
(\mathrm{n}=628)\end{array}$ & $\begin{array}{l}\text { Infected } \\
\text { people } \\
(\mathrm{n}=135)\end{array}$ & $\begin{array}{l}\text { Total } \\
(\mathrm{n}=387)\end{array}$ & $\begin{array}{l}\text { Non-infected } \\
\text { people } \\
\qquad(n=300)\end{array}$ & $\begin{array}{l}\text { Infected } \\
\text { people } \\
(\mathrm{n}=87)\end{array}$ & $\begin{array}{l}\text { Total } \\
(\mathrm{n}=376)\end{array}$ & $\begin{array}{l}\text { Non-infected } \\
\text { people } \\
(\mathrm{n}=338)\end{array}$ & $\begin{array}{l}\text { Infected } \\
\text { people } \\
(n=48)\end{array}$ \\
\hline & $\mathrm{n}(\%)$ & $\mathrm{n}(\%)$ & $\mathrm{n}(\%)$ & $\mathrm{n}(\%)$ & $\mathrm{n}(\%)$ & $\mathrm{n}(\%)$ & $\mathrm{n}(\%)$ & $\mathrm{n}(\%)$ & $\mathrm{n}(\%)$ \\
\hline \multicolumn{10}{|l|}{ Gender } \\
\hline Women & $269(35.3)$ & $402(64.0)$ & $50(37.0)$ & $138(35.7)$ & $107(35.7)$ & $31(35.6)$ & $131(34.8)$ & $112(34.1)$ & $19(39.6)$ \\
\hline Men & $487(63.8)$ & $219(34.9)$ & $85(63.0)$ & $249(64.3)$ & $193(64.3)$ & $56(64.4)$ & $238(63.3)$ & 209 (63.7) & $29(60.4)$ \\
\hline Prefer not to say & $7(0.9)$ & $7(1.1)$ & - & - & - & - & $7(1.9)$ & $7(2.1)$ & - \\
\hline $\operatorname{Age}^{a}$ & $36.7 \pm 15.1$ & $36.4 \pm 15.0$ & $38.3 \pm 15.7$ & $43.9 \pm 16.6$ & $43.9 \pm 16.8$ & $43.8 \pm 15.9$ & $29.3 \pm 8.6$ & $29.5 \pm 8.6$ & $28.2 \pm 9.1$ \\
\hline \multicolumn{10}{|l|}{ Education } \\
\hline $\begin{array}{l}\text { Junior high school } \\
\text { graduate }\end{array}$ & $36(4.7)$ & $30(4.8)$ & $6(4.4)$ & $10(2.6)$ & $8(2.7)$ & $2(2.3)$ & $26(6.9)$ & $22(6.7)$ & $4(8.3)$ \\
\hline High school graduate & $274(35.9)$ & $231(36.8)$ & $43(31.9)$ & $98(25.3)$ & $81(27.0)$ & $17(19.5)$ & $176(46.8)$ & $150(45.7)$ & $26(54.2)$ \\
\hline
\end{tabular}




\begin{tabular}{|c|c|c|c|c|c|c|c|c|c|}
\hline $\begin{array}{l}\text { Vocational } \\
\text { school/junior college } \\
\text { graduate }\end{array}$ & $83(10.9)$ & $68(10.8)$ & $15(11.1)$ & $53(13.7)$ & $40(13.3)$ & $13(14.9)$ & $30(8.0)$ & $28(8.5)$ & $2(4.2)$ \\
\hline $\begin{array}{l}\text { University graduate } \\
\text { or above }\end{array}$ & $370(48.5)$ & $299(47.6)$ & $71(52.6)$ & $226(58.4)$ & $171(57.0)$ & $55(63.2)$ & $144(38.3)$ & $128(39.0)$ & $16(33.3)$ \\
\hline \multicolumn{10}{|l|}{ Household income } \\
\hline $\begin{array}{l}\quad \leq 4270,000 \text { JPY or } \leq \\
380,000 \text { SEK }\end{array}$ & $367(48.1)$ & $308(49.0)$ & $59(43.7)$ & $162(41.9)$ & $130(43.3)$ & $32(36.8)$ & $205(54.5)$ & $178(54.3)$ & $27(56.3)$ \\
\hline $\begin{array}{l}>4270,000 \mathrm{JPY} \text { or }> \\
380000 \mathrm{SEK}\end{array}$ & $396(51.9)$ & $320(51.0)$ & $76(56.3)$ & $225(58.1)$ & $170(56.7)$ & $55(63.2)$ & $171(45.5)$ & $150(45.7)$ & $21(43.8)$ \\
\hline \multicolumn{10}{|l|}{ Worker status } \\
\hline Full time & $371(48.6)$ & $291(46.3)$ & $80(59.3)$ & $208(53.7)$ & $148(49.3)$ & $60(69.0)$ & $163(43.4)$ & $143(43.6)$ & $20(41.7)$ \\
\hline Part time & $76(10.0)$ & $63(10.0)$ & $13(9.6)$ & $59(15.2)$ & $48(16.0)$ & $11(12.6)$ & $17(4.5)$ & $15(4.6)$ & $2(4.2)$ \\
\hline Unemployed & $155(20.3)$ & $137(21.8)$ & $18(13.3)$ & $88(22.7)$ & $75(25.0)$ & $13(14.9)$ & $67(17.8)$ & $62(18.9)$ & $5(10.4)$ \\
\hline Student & $161(21.1)$ & $137(21.8)$ & $24(17.8)$ & $32(8.3)$ & $29(9.7)$ & $3(3.4)$ & $129(34.3)$ & $108(32.9)$ & $21(43.8)$ \\
\hline \multicolumn{10}{|l|}{ Living status } \\
\hline Alone & $202(26.5)$ & $165(26.3)$ & $37(27.4)$ & $94(24.3)$ & $72(24.0)$ & $22(25.3)$ & $108(28.7)$ & $93(28.4)$ & $15(31.3)$ \\
\hline With family or partner & $546(71.6)$ & $451(71.8)$ & $95(70.4)$ & $290(74.9)$ & $226(75.3)$ & $64(73.6)$ & $256(68.1)$ & $225(68.6)$ & $31(64.6)$ \\
\hline With others & $15(2.0)$ & $12(1.9)$ & $3(2.2)$ & $3(0.8)$ & $2(0.7)$ & $1(1.1)$ & $12(3.2)$ & $10(3.0)$ & $2(4.2)$ \\
\hline
\end{tabular}




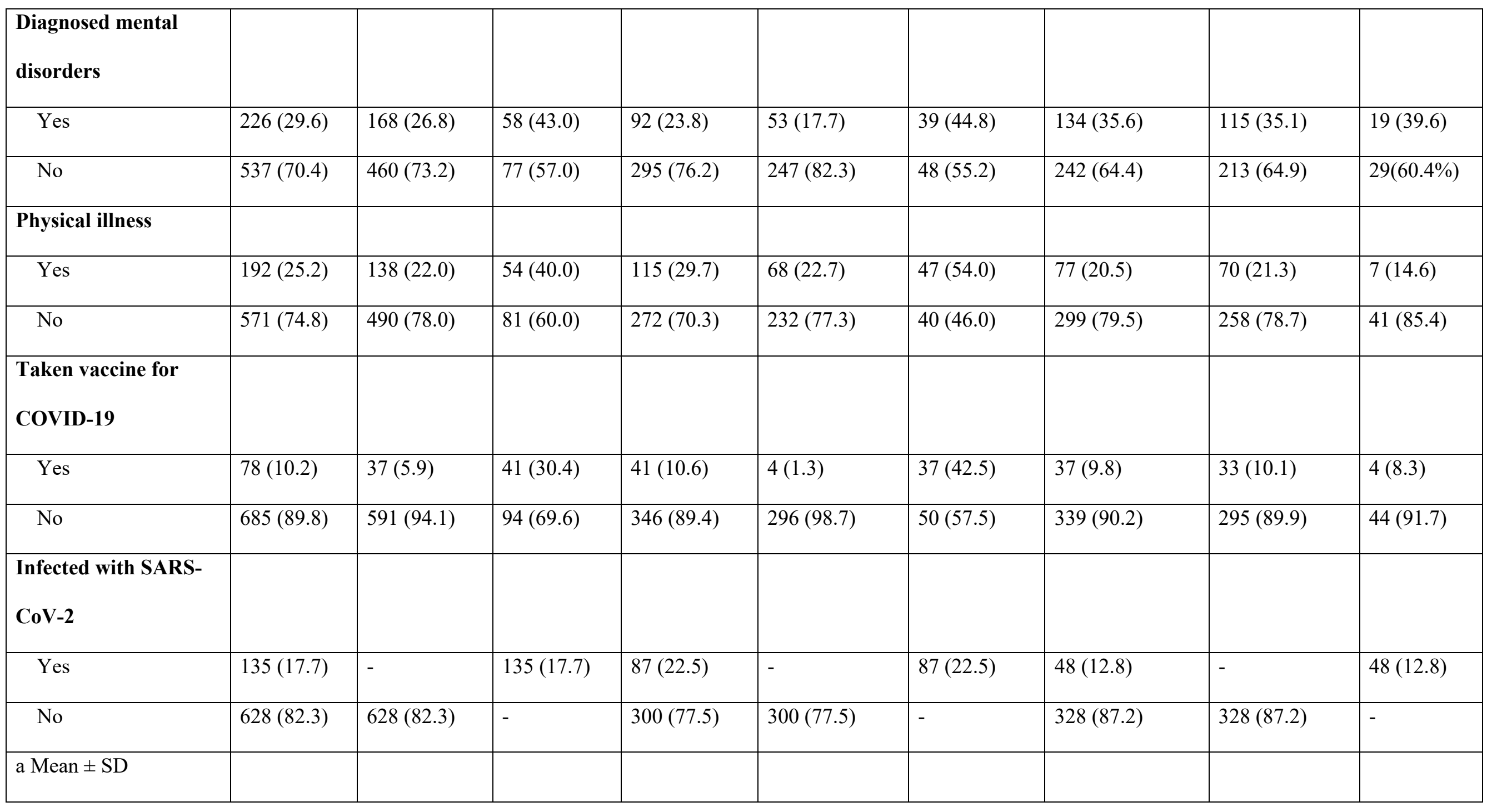


Table 2. Demographic data of participants infected with SARS-CoV-2

\begin{tabular}{|c|c|c|c|c|c|c|c|c|c|}
\hline & \multicolumn{3}{|l|}{ Overview } & \multicolumn{3}{|l|}{ Japanese } & \multicolumn{3}{|l|}{ Swedish } \\
\hline & $\begin{array}{l}\text { Non- } \\
\text { infected } \\
\text { people } \\
(n=628)\end{array}$ & $\begin{array}{l}\text { Without } \\
\text { sequelae } \\
(\mathrm{n}=80)\end{array}$ & $\begin{array}{l}\text { With } \\
\text { sequelae } \\
(\mathrm{n}=55)\end{array}$ & $\begin{array}{l}\text { Non- } \\
\text { infected } \\
\text { people } \\
(\mathrm{n}=300)\end{array}$ & $\begin{array}{l}\text { Without } \\
\text { sequelae } \\
(n=47)\end{array}$ & $\begin{array}{l}\text { With } \\
\text { sequelae } \\
(\mathrm{n}=40)\end{array}$ & $\begin{array}{l}\text { Non- } \\
\text { infected } \\
\text { people } \\
(\mathrm{n}=328)\end{array}$ & $\begin{array}{l}\text { Without } \\
\text { sequelae } \\
(n=33)\end{array}$ & $\begin{array}{l}\text { With } \\
\text { sequelae } \\
(\mathrm{n}=15)\end{array}$ \\
\hline & $\mathrm{n}(\%)$ & $\mathrm{n}(\%)$ & $\mathrm{n}(\%)$ & $\mathrm{n}(\%)$ & $\mathrm{n}(\%)$ & $\mathrm{n}(\%)$ & $\mathrm{n}(\%)$ & $\mathrm{n}(\%)$ & $\mathrm{n}(\%)$ \\
\hline $\operatorname{Age}^{b}$ & $36.4 \pm 15.0$ & $38.0 \pm 16.5$ & $38.6 \pm 14.7$ & $43.9 \pm 16.8$ & $45.28 \pm 16.7$ & $42.1 \pm 14.9$ & $29.5 \pm 8.6$ & $27.6 \pm 9.0$ & $29.4 \pm 9.4$ \\
\hline Diagnosed mental illness (yes) & $168(26.8)$ & $25(31.3)$ & $33(60.0)$ & $53(17.7)$ & $14(29.8)$ & $25(62.5)$ & $115(35.1)$ & $11(33.3)$ & $8(53.3)$ \\
\hline Depression & $129(20.5)$ & $14(17.5)$ & $21(38.2)$ & $40(13.3)$ & $6(12.8)$ & $15(37.5)$ & $89(27.1)$ & $8(24.2)$ & $6(40.0)$ \\
\hline $\begin{array}{l}\text { Bipolar disorder or } \\
\text { schizophrenia }\end{array}$ & $12(1.9)$ & $4(5.0)$ & $8(14.5)$ & $8(2.7)$ & $2(4.3)$ & $8(20.0)$ & $4(1.2)$ & $2(6.1)$ & - \\
\hline Anxiety disorder & $65(10.4)$ & $6(7.5)$ & $16(29.1)$ & $14(4.7)$ & $3(6.4)$ & $14(35.0)$ & $51(15.5)$ & $3(9.1)$ & $2(13.3)$ \\
\hline PTSD & $11(1.8)$ & $2(2.5)$ & $5(9.1)$ & $2(0.7)$ & $2(4.3)$ & $5(12.5)$ & $9(2.7)$ & - & - \\
\hline OCD & $10(1.6)$ & $2(2.5)$ & $6(10.9)$ & $1(0.3)$ & $1(2.1)$ & $6(15.0)$ & $9(2.7)$ & $1(3.0)$ & $1(13.3)$ \\
\hline Panic disorder & $27(4.3)$ & $5(6.3)$ & $11(20.0)$ & $9(3.0)$ & $4(8.5)$ & $10(25.0)$ & $18(5.5)$ & $1(3.0)$ & $1(6.7)$ \\
\hline
\end{tabular}




\begin{tabular}{|c|c|c|c|c|c|c|c|c|c|}
\hline Eating disorders & $16(2.5)$ & $3(3.8)$ & $6(10.9)$ & $1(0.3)$ & $3(6.4)$ & $4(10.0)$ & $15(4.6)$ & - & $2(13.3)$ \\
\hline Substance Use Disorder & $4(0.6)$ & $3(3.8)$ & $6(10.9)$ & - & $3(6.4)$ & $5(12.5)$ & $4(1.2)$ & - & $1(6.7)$ \\
\hline ADHD & $5(0.8)$ & $1(1.3)$ & $1(1.8)$ & - & - & - & $5(1.5)$ & $1(3.0)$ & $1(6.7)$ \\
\hline ADD & $1(0.2)$ & - & - & - & - & & $1(0.3)$ & & \\
\hline ASD & $5(0.8)$ & - & - & $1(0.3)$ & - & - & $4(1.2)$ & - & - \\
\hline $\begin{array}{l}\text { Schizophrenia personality } \\
\text { disorder }\end{array}$ & $1(0.2)$ & - & - & & - & - & $1(0.3)$ & & \\
\hline Borderline personality disorder & $1(0.2)$ & - & - & & - & - & $1(0.3)$ & & \\
\hline Physical illness (yes) & $138(22.0)$ & $21(26.3)$ & $33(60.0)$ & $68(22.7)$ & $17(36.2)$ & $30(75.0)$ & $70(21.3)$ & $4(12.1)$ & $3(20.0)$ \\
\hline High blood pressure & $51(8.1)$ & $12(15.0)$ & $25(45.5)$ & $43(14.3)$ & $11(23.4)$ & $25(62.5)$ & $8(2.4)$ & $1(3.0)$ & - \\
\hline Asthma & $48(7.6)$ & $6(7.5)$ & $12(21.8)$ & $13(4.3)$ & $3(6.4)$ & $9(22.5)$ & $35(10.7)$ & $3(9.1)$ & $3(20.0)$ \\
\hline Diabetes & $23(3.7)$ & $6(7.5)$ & $11(20.0)$ & $15(5.0)$ & $5(10.6)$ & $11(27.5)$ & $8(2.4)$ & $1(3.0)$ & - \\
\hline Cancer & & $2(2.6)$ & & - & $2(4.2)$ & - & - & - & - \\
\hline Renal failure & & $1(1.3)$ & - & - & $1(2.1)$ & - & - & - & - \\
\hline Chronic nephritis & & $1(1.3)$ & - & - & $1(2.1)$ & - & - & - & - \\
\hline Other & $28(4.5)$ & & & $8(2.7)$ & & & $20(6.1)$ & & \\
\hline Hospitalization (yes) & - & $21(26.3)$ & $27(49.1)$ & - & $21(44.7)$ & $27(67.5)$ & - & - & - \\
\hline
\end{tabular}




\begin{tabular}{|c|c|c|c|c|c|c|c|c|c|}
\hline Ventilator & - & $9(11.3)$ & $14(25.5)$ & - & $9(19.1)$ & $14(35.0)$ & - & - & - \\
\hline Days to recovery ${ }^{b}$ & - & $24.1 \pm 31.2$ & $33.8 \pm 37.7$ & - & $31.7 \pm 35.0$ & $33.9 \pm 32.2$ & - & $15.8 \pm 16.3$ & $\begin{array}{l}33.3 \pm \\
50.8\end{array}$ \\
\hline Infectious symptoms (yes) & - & $65(81.3)$ & $55(100.0)$ & - & $35(74.5)$ & $40(100)$ & - & $30(90.9)$ & $15(100.0)$ \\
\hline Heat & - & $43(53.8)$ & $40(72.7)$ & - & $26(55.3)$ & $28(70.0)$ & - & $17(51.5)$ & $12(80.0)$ \\
\hline Cough & - & $26(32.5)$ & $27(49.1)$ & - & $10(21.3)$ & $19(47.5)$ & - & $16(48.5)$ & $8(53.3)$ \\
\hline Fatigue, tiredness & - & $37(46.3)$ & $28(50.9)$ & - & $13(27.7)$ & $17(42.5)$ & - & $24(72.7)$ & $11(73.3)$ \\
\hline Dyspnea & - & $5(6.3)$ & $11(20.0)$ & - & $3(6.4)$ & $10(25.0)$ & - & $2(6.1)$ & $1(6.7)$ \\
\hline Smell disorder & - & $13(16.3)$ & $19(34.5)$ & - & $3(6.4)$ & $11(27.5)$ & - & $10(30.3)$ & $8(53.3)$ \\
\hline Dysgeusia & - & $18(22.5)$ & $19(34.5)$ & - & $6(12.8)$ & $12(30.0)$ & - & $12(36.4)$ & $7(46.7)$ \\
\hline Increased sputum & - & $8(10.0)$ & $9(16.4)$ & - & $2(4.3)$ & $5(12.5)$ & - & $6(18.2)$ & $4(26.7)$ \\
\hline Chest pain & - & $4(5.0)$ & $11(20.0)$ & - & $2(4.3)$ & $9(22.5)$ & - & $2(6.1)$ & $2(13.3)$ \\
\hline Joint pain & - & $10(12.5)$ & $17(30.9)$ & - & $2(4.3)$ & $8(20.0)$ & - & $8(24.2)$ & $9(60.0)$ \\
\hline Muscle pain & - & $10(12.5)$ & $13(23.6)$ & - & $1(2.1)$ & $8(20.0)$ & - & $9(27.3)$ & $5(33.3)$ \\
\hline Headache & - & $22(27.5)$ & $17(30.9)$ & - & $3(6.4)$ & $9(22.5)$ & - & $19(57.6)$ & $8(53.3)$ \\
\hline Palpitations & - & $1(1.3)$ & $9(16.4)$ & - & $1(2.1)$ & $5(12.5)$ & - & - & $4(26.7)$ \\
\hline Hair loss & - & $1(1.3)$ & $3(5.5)$ & - & $1(2.1)$ & $3(7.5)$ & - & - & - \\
\hline
\end{tabular}




\begin{tabular}{|c|c|c|c|c|c|c|c|c|c|}
\hline Insomnia & - & $4(5.0)$ & $4(7.3)$ & - & $1(2.1)$ & $2(5.0)$ & - & $3(9.1)$ & $2(13.3)$ \\
\hline Anxiety & - & $4(5.0)$ & $7(12.7)$ & - & $3(6.4)$ & $5(12.5)$ & - & $1(3.0)$ & $2(13.3)$ \\
\hline Depression & - & $3(3.8)$ & $6(10.9)$ & - & $2(4.3)$ & $4(10.0)$ & - & $1(3.0)$ & $2(13.3)$ \\
\hline Sore throat & - & $4(5.0)$ & $3(5.5)$ & - & $2(4.3)$ & $2(5.0)$ & - & $2(6.1)$ & $1(6.7)$ \\
\hline Urination disorder & - & $1(1.3)$ & - & - & $1(1.1)$ & - & - & - & - \\
\hline Nasal congestion & - & - & $1(1.8)$ & - & - & $1(2.5)$ & - & - & - \\
\hline Chills & - & $1(1.3)$ & - & - & $1(1.1)$ & - & - & - & - \\
\hline Diarrhea & - & - & $1(1.8)$ & - & - & - & - & - & $1(6.7)$ \\
\hline Nosebleed & - & $1(1.3)$ & - & - & - & - & - & $1(3.0)$ & - \\
\hline Herpes labialis & - & $1(1.3)$ & - & - & - & - & - & $1(3.0)$ & - \\
\hline Common cold & - & $1(1.3)$ & - & - & - & - & - & $1(3.0)$ & - \\
\hline Respiratory tract infection & - & $1(1.3)$ & - & - & - & - & & $1(3.0)$ & - \\
\hline Sequelae(yes) & - & - & - & - & - & & - & - & \\
\hline Heat & - & - & $7(12.7)$ & - & - & $4(10.0)$ & - & - & $3(20.0)$ \\
\hline Cough & - & - & $8(14.5)$ & - & - & $6(15.0)$ & - & - & $2(13.3)$ \\
\hline Fatigue, tiredness & - & - & $19(34.5)$ & - & - & $10(25.0)$ & - & - & $9(60.0)$ \\
\hline Dyspnea & - & - & $5(9.1)$ & - & - & $4(10.0)$ & - & - & $1(6.7)$ \\
\hline
\end{tabular}




\begin{tabular}{|c|c|c|c|c|c|c|c|c|c|}
\hline Smell disorder & - & - & $12(21.8)$ & - & - & $7(17.5)$ & - & - & $5(33.3)$ \\
\hline Dysgeusia & - & - & $13(23.6)$ & - & - & $11(27.5)$ & - & - & $2(13.3)$ \\
\hline Increased sputum & - & - & $6(10.9)$ & - & - & $4(10.0)$ & - & - & $2(13.3)$ \\
\hline Chest pain & - & - & $7(12.7)$ & - & - & $6(15.0)$ & - & - & $1(6.7)$ \\
\hline Joint pain & - & - & $5(9.1)$ & - & - & $3(7.5)$ & - & - & $2(13.3)$ \\
\hline Muscle pain & - & - & $6(10.9)$ & - & - & $4(10.0)$ & - & - & $2(13.3)$ \\
\hline Headache & - & - & $5(9.1)$ & - & - & $3(7.5)$ & - & - & $2(13.3)$ \\
\hline Palpitations & - & - & $6(10.9)$ & - & - & $5(12.5)$ & - & - & $1(6.7)$ \\
\hline Hair loss & - & - & $5(9.1)$ & - & - & $4(10.0)$ & - & - & $1(6.7)$ \\
\hline Insomnia & - & - & $5(9.1)$ & - & - & $3(7.5)$ & - & - & $2(13.3)$ \\
\hline Anxiety & - & - & $9(16.4)$ & - & - & $7(17.5)$ & - & - & $2(13.3)$ \\
\hline Depression & - & - & $7(12.7)$ & - & - & $4(10.0)$ & - & - & $3(20.0)$ \\
\hline Sore throat & - & - & $1(1.8)$ & - & - & $1(2.5)$ & - & - & - \\
\hline $\begin{array}{l}\text { Feeling like stinging in your } \\
\text { left hand }\end{array}$ & - & - & $1(1.8)$ & - & - & - & - & - & $1(6.7)$ \\
\hline Clinical scales & & & & & & & - & - & \\
\hline FCV-19S $\geq 18$ & $269(42.8)$ & $35(43.8)$ & $40(72.7)$ & $191(63.7)$ & $31(66.0)$ & $36(90.0)$ & $78(23.8)$ & $4(12.1)$ & $4(26.7)$ \\
\hline
\end{tabular}




\begin{tabular}{|c|c|c|c|c|c|c|c|c|c|}
\hline FCV-19S $<17$ & $359(57.2)$ & $45(56.3)$ & $15(19.5)$ & $109(36.3)$ & $16(34.0)$ & $4(10.0)$ & $250(76.2)$ & $29(87.9)$ & $11(73.3)$ \\
\hline PHQ $\geq 10$ & $190(30.3)$ & $21(26.3)$ & $32(58.2)$ & $72(24.0)$ & $14(30.0)$ & $25(62.5)$ & $118(36.0)$ & $7(21.2)$ & $7(46.7)$ \\
\hline PHQ $<9$ & 438 (69.7) & $59(73.8)$ & $23(41.8)$ & $228(76.0)$ & $33(70.2)$ & $15(37.5)$ & $210(64.0)$ & $26(78.8)$ & $8(53.3)$ \\
\hline $\mathrm{GAD} \geq 10$ & $15(16.7)$ & $9(11.3)$ & $24(43.6)$ & $45(15.0)$ & $7(14.9)$ & $20(50.0)$ & $60(18.3)$ & $2(6.1)$ & $4(26.7)$ \\
\hline GAD $<9$ & $523(83.3)$ & $71(88.8)$ & $31(56.4)$ & $255(85.0)$ & $40(85.1)$ & $20(50.0)$ & $268(81.7)$ & $31(93.9)$ & $11(73.3)$ \\
\hline IES-R $\geq 25$ & $192(30.6)$ & $31(38.8)$ & $37(67.3)$ & $95(31.7)$ & $21(44.7)$ & $30(75.0)$ & $97(29.6)$ & $10(30.3)$ & $7(46.7)$ \\
\hline IES-R $<24$ & $436(69.4)$ & $49(61.3)$ & $18(32.7)$ & $205(68.3)$ & $26(55.3)$ & $10(25.0)$ & $231(70.4)$ & $23(69.7)$ & $8(53.3)$ \\
\hline \multicolumn{10}{|l|}{$\mathrm{b}$ Mean $\pm \mathrm{SD}$} \\
\hline \multicolumn{10}{|c|}{ Note. ADD, attention deficit disorder; ADHD, attention deficit hyperactivity disorder; ASD, autism spectrum disorder; COVID-19, coronavirus disease 2019; } \\
\hline
\end{tabular}


Table 3. The results of the logistic regression model

\begin{tabular}{|c|c|c|c|c|c|c|c|}
\hline Variable & & $\beta$ & $S E$ & Odd ratios & \multicolumn{2}{|c|}{$95 \% \mathrm{CI}$} & \multirow[t]{2}{*}{$P$-value } \\
\hline Dependent & Independent & & & & & & \\
\hline \multirow[t]{3}{*}{ FCV-19S } & Country & 3.08 & 0.53 & 21.73 & 7.74 & 61.01 & $<.001$ \\
\hline & Sequelae & 1.40 & 0.49 & 4.07 & 1.57 & 10.56 & .004 \\
\hline & Gender & 1.14 & 0.51 & 3.11 & 1.15 & 8.45 & .026 \\
\hline \multirow[t]{3}{*}{ PHQ-9 } & Sequelae & 1.22 & 0.40 & 3.38 & 1.54 & 7.41 & .002 \\
\hline & Gender & 1.03 & 0.42 & 2.80 & 1.22 & 6.44 & .015 \\
\hline & Mental illness & 0.94 & 0.40 & 2.55 & 1.17 & 5.56 & .018 \\
\hline \multirow[t]{4}{*}{ GAD-7 } & Country & 1.79 & 0.61 & 5.96 & 1.79 & 19.86 & .004 \\
\hline & Sequelae & 1.53 & 0.51 & 4.64 & 1.72 & 12.51 & .002 \\
\hline & Mental illness & 1.41 & 0.51 & 4.10 & 1.52 & 11.09 & .005 \\
\hline & Age & -0.05 & 0.02 & 0.95 & 0.91 & 0.99 & .009 \\
\hline \multirow[t]{3}{*}{ IES-R } & Ventilator & -0.90 & 0.28 & 4.88 & 1.48 & 16.08 & .009 \\
\hline & Sequelae & 1.58 & 0.61 & 2.48 & 1.15 & 5.34 & .021 \\
\hline & Mental illness & 0.91 & 0.39 & 2.16 & 1.01 & 4.61 & .048 \\
\hline
\end{tabular}

Note. CI, confidence interval; FCV-19S, fear of COVID-19 scale; GAD-7, deneralised anxiety disorder 7-item scale ; IES-R, impact of event scale-revised; ; PHQ-9, patient health questionnaire 9item scale; SE, standard error. 
Figures

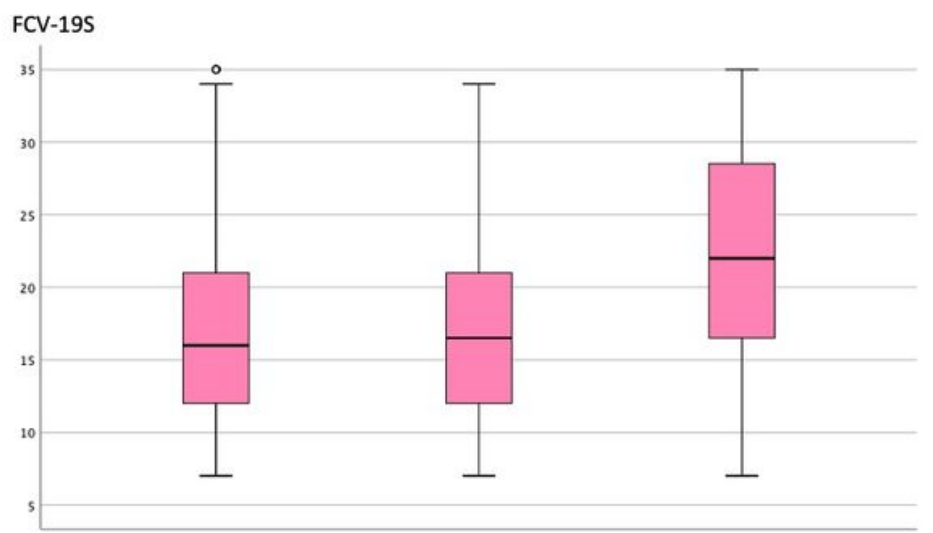

Non-infected

without sequelae

with sequelae

GAD-7

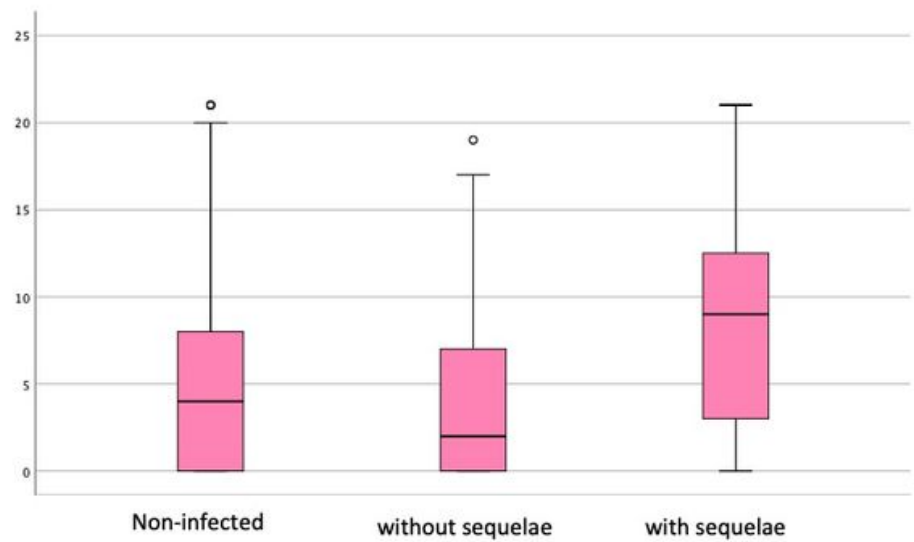

PHQ-9

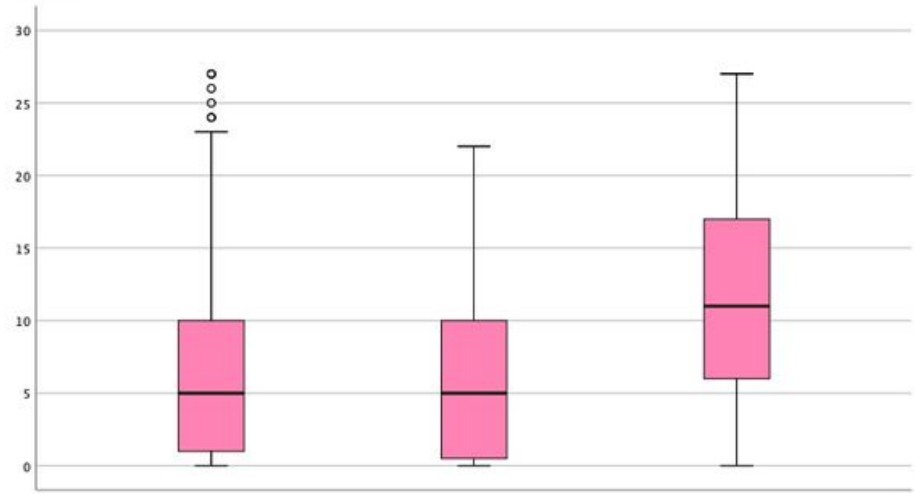

Non-infected

without sequelae

with sequelae

ISE-R

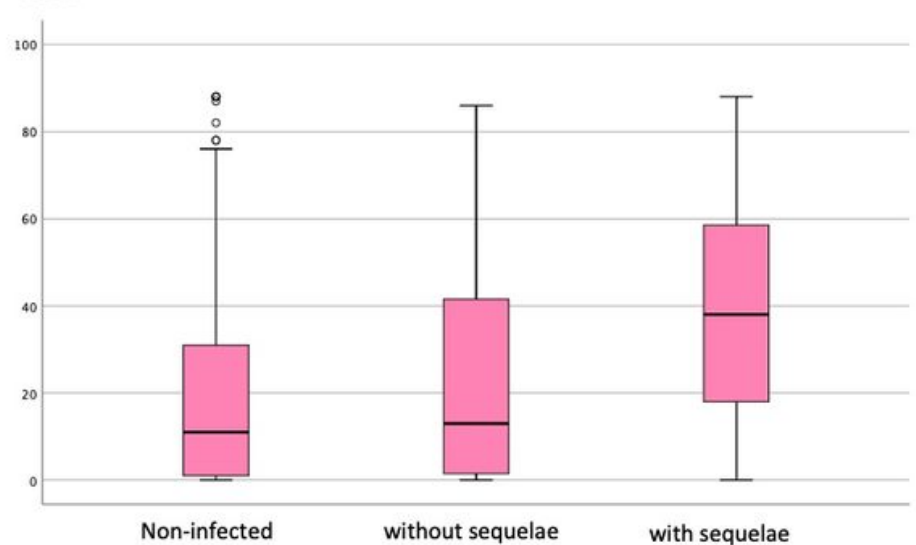

Figure 1

The results of the Kruskal-Wallis test 


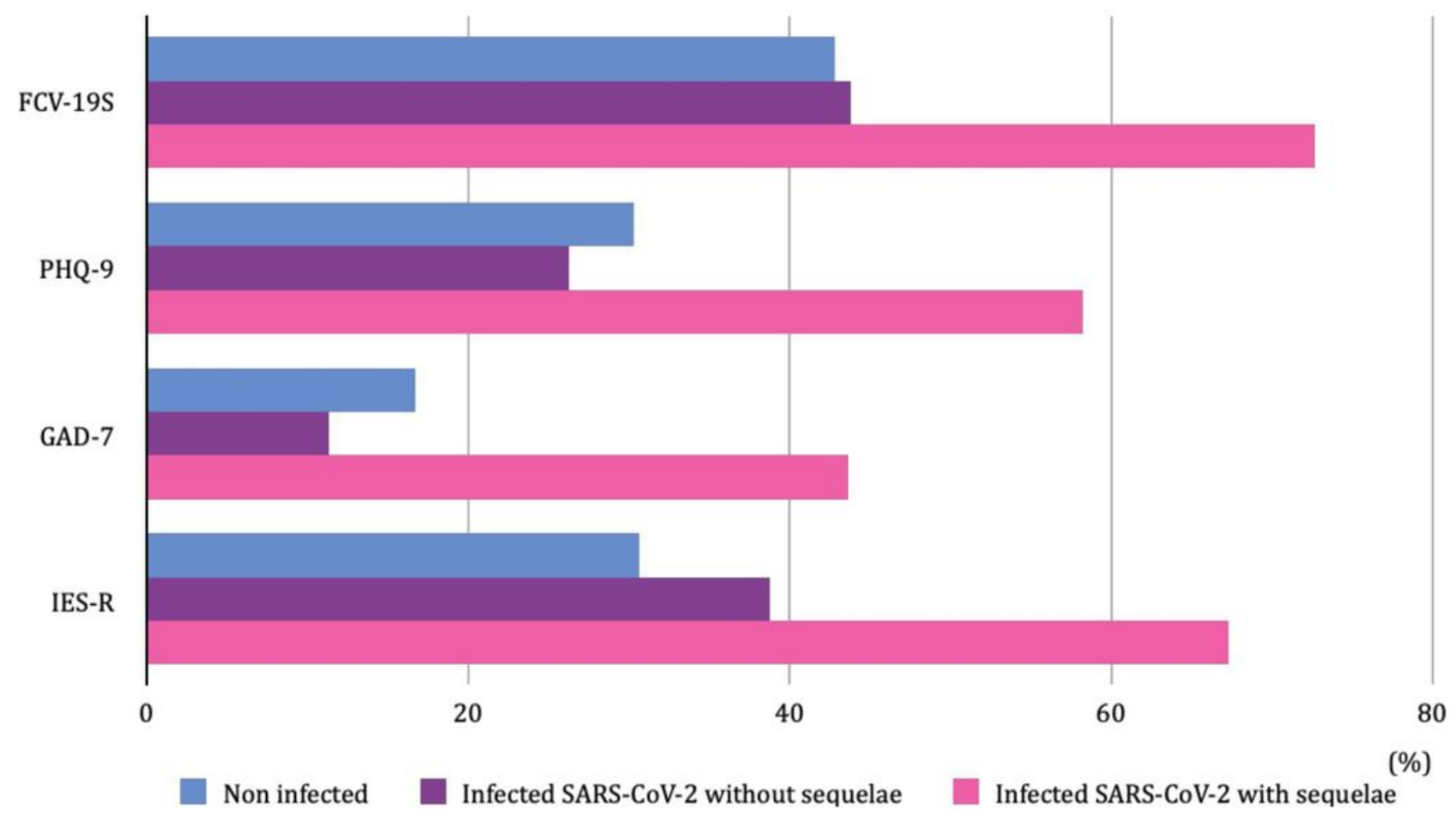

Figure 2

The incidence of clinically significant psychiatric symptoms

\section{Supplementary Files}

This is a list of supplementary files associated with this preprint. Click to download.

- STROBEchecklist.doc 